\title{
Road to Women Empowerment in Cambodia; A Leadership and Education approach
}

\author{
AMNA YAMEEN \\ Assistant Professor, Bahria Business School, Bahria University, Islamabad, Pakistan. \\ Email: amnayameen@bahria.edu.pk \\ NIDA KAMAL \\ Senior Lecturer, Bahria Business School, Bahria University, Islamabad, Pakistan. \\ Email: nidakamal.buic@bahria.edu.pk
}

\section{HINA SAMDANI}

Senior Assistant Professor, Bahria Business School, Bahria University, Islamabad, Pakistan.

Email: hina@bahria.edu.pk

\begin{abstract}
Women empowerment is considered a complex and multidimensional phenomenon because it is heavily embedded in the context in which it is being practiced. The construct of empowerment can be viewed from the lens of a process (i.e. elements facilitating individual's or group's empowerment) and an outcome (i.e. empowered individuals or groups). The study is a qualitative analysis that explores empowerment through the lens of agency and opportunity structure. The present study has been conducted on students of Harpswell Foundation, Phnom Penh, Cambodia. Harpswell Foundation is a residential facility that invests in female high school graduates by providing them access to higher education, housing, and leadership opportunities. Empirical results reveal that the processes and program components of the Harpswell Foundation create an enabling environment for young women which leads to the development of their personal skills, self-awareness, career planning, economic stability, and self-sustainability. The graduates of Harpswell Foundation play a significant role in creating a landscape for empowered women in Cambodia as most of these graduates, being the first generation of their family to attend university, are either self-employed, work at a top tier company or non-profit, have pursued higher education, and have created a significant difference in the economic conditions of their family.
\end{abstract}

Keywords: Women Empowerment, Leadership, Agency, Group Education, Civil Society.

\section{Introduction}

Women empowerment is considered a complex and multidimensional phenomenon because it is heavily embedded in the context in which it is being practiced (Karim, Picard, Gillingham, \& Berkowitz, 2014). The agenda of women empowerment was brought at the forefront of global issues at the Beijing Conference held in 1995. Since then, the term women empowerment has been extensively researched and intensive efforts have been made to incorporate it in the development sector, both in theory and practice (Larsson, 2016).

In the international development sector, women empowerment has been theorized from an individual perspective (Grabe, 2012). According to this concept, a woman always has the power to shape her destiny and bring about the requisite change in surroundings. If women are provided with the required material resources that they lack, they can transform their lives and bring about a change in their environment. The 
feminist theorists have heavily criticized this concept, as it portrays empowerment as an option that a woman can exercise if she chooses to do so. It ignores the impact of surroundings and other barriers that might be creating a hindrance in empowering a woman (Cornwall \& Edwards, 2010). A research conducted by Stromquist (1995) argued that four components need to be included to complete the definition of empowerment. These elements are women's understanding of conditions leading to their subordination in the society (cognitive), belief in their capacity to change their conditions (psychological), ability to be involved in activities that generate financial independence (economic), and realization of political and social inequalities in the environment and ability to institute social change (political).

With the advent of feminist movements, more emphasis has been laid on understanding empowerment as a factor that comes from within an individual and not something that is dependent solely on the provision of material resources (Rowlands, 1995). This notion has given the need to understand empowerment as a process (Kabeer, 1999; Larsson, 2016). According to Karim, Picard, Gillingham and Berkowitz (2014) empowerment is the sum of collective changes needed by a woman to achieve her universal rights. The changes that a woman experiences are due to the interplay of three factors: a woman's own capabilities (agency), the environment that shapes her choices (structure), and the power relations with which she must negotiate to exercise her choices (relations). Kabeer (1999) furthermore describes how power is at the core of women empowerment. If individuals have the power or ability to exercise their choices it is only then that they develop the capacity to make transformative changes in their lives. Kabeer (1999) summarized the idea by viewing women empowerment through a three-dimensional framework: agency, resources, and achievements. Empowerment is not a trait or skill that can be developed overnight. Individuals need to be provided enabling environments that will help them progress towards the required development outcomes. Different pathways can lead to women empowerment. Research has shown that access to incomegenerating activities, no matter how small, helps women exert greater control over their household decisions. Beneria and Roldan (1987) conducted a study on 140 women and concluded that participation in income generation led to higher self-esteem and involvement in household decisions. Projects that provide training in literacy skills coupled with critical thinking have also been successful in helping women break oppressive barriers. However, most studies have supported the creation of a shared space that provided 'conscious-raising' experiences for participating women. Other elements that have proved effective in the empowerment process include role models, social space, and/or network of friends (Beneria \& Roldan, 1987).

In Cambodia, women empowerment has been a growing area of concern as it is crucial to the progression and development of this country. Making $51 \%$ of the Cambodian population, these women are constrained by society's patriarchal norms and practices. Due to these constraints, women do not have equal representation in social, economic, and political domains. Education, a key tool that can facilitate the empowerment of women is, most of the time prioritized for men. Many families choose to invest in the education of boys as they will end up being breadwinners of the family. Financial constraints are not the only barrier for women to pursue their studies. Most provinces in Cambodia lack quality higher education institutes. If females choose to leave their respective provinces to study in Phnom Penh (the capital city of Cambodia), they are faced with housing and safety challenges (Booth, 2014). Hence, Harpswell Foundation, a residential leadership facility founded in 2003 by Alan Lightman, aims to alleviate these constraints towards the education of women by aiming to "empower a new generation of leaders in Cambodia".

\section{Research Questions}

1: How is the Harpswell Foundation creating empowered women?

2: What role do Harpswell graduates play in changing the status quo of women in Cambodian society? 


\section{Research Objectives}

1: To explore how the Harpswell Foundation is creating empowered Cambodian women.

2: To examine the factors that create agency and opportunity structure for Harpswell women and lead to their empowerment.

3: To examine the outcomes resulting from the program structure of the Harpswell Foundation.

4: To explore the impact of Harpswell women on Cambodian society.

\section{Materials and Methods}

The study is a qualitative analysis that investigates how the Harpswell Foundation is creating empowered women by enhancing their agency and providing them with an opportunity structure. The study is descriptive and has been conducted using a case study research method. Data was gathered through semistructured interviews from 20 students of BT dormitory at Harpswell Foundation. Random sampling was used to select the target audience. The students belonged to different age groups ranging from 20-24. Each interview was conducted on a face-to-face basis and lasted from 30-35 minutes. The responses were audiotaped and later transcribed. The accuracy of the transcription was ensured through double peer-review method. Data analysis was done by qualitatively analyzing student's responses to the interview questions. Qualitative software QSR NVivo 12.0 was used for coding the transcripts. Any contradictions appearing in the respondents' answers were removed, resulting in generation of themes explicitly evident in the respondents' transcriptions.

\section{Conceptual Framework}

The conceptual framework presented in Figure 1 has been used to guide the analysis of this study. The framework is based on the research work of Smulovitz and Petesch (2005). The framework has strong underpinnings in the works of Sen (1985); Sen (1992); Kabeer (1999); Krishna (2003); Malhotra et al., (2002); Smulovitz, Walton, and Petesch (2003).

The framework of Empowerment is attained through a combination of agency and opportunity structure. Agency is the ability of an individual or group to create options and make meaningful choices. Opportunity structure refers to the context in which the individual/group is required to function. It can enhance or impede the individual's/group's ability to exercise their choices. The study will examine the various factors that create the agency and opportunity structure for Harpswell women and hence lead to their empowerment.

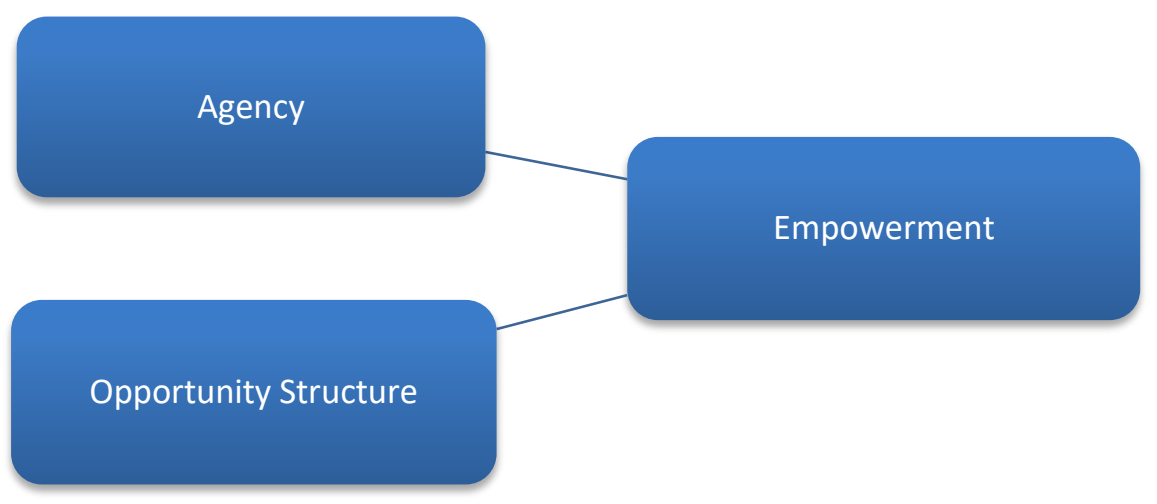

Figure 1. Conceptual Framework: Agency, Opportunity Structure, and Empowerment 


\section{Results}

The qualitative analysis of the interviews generated four themes as discussed below:

\section{Role of Harpswell Foundation in Providing Access to Higher Education}

An analysis of the results revealed that the majority of students residing at the Harpswell Foundation belong to low-income background and hail from various provinces (outside of Phnom Penh) that do not have opportunities for higher education. In the interviews, students reported that they would have been lost without the opportunities provided to them by the Harpswell Foundation. Most of the students come from families, which would never have been able to send them to Phnom Penh to get higher education due to financial burdens. Harpswell opened doors to these students and supported and encouraged them to go forth and pursue their dreams without financial constraints holding them back. Most of the students agree that without Harpswell, they would have missed out on most opportunities that life had to offer.

Harpswell provides significant financial support to the students, from covering the cost of food, daily necessities, Internet facilities, accommodation, travel, to health expenses. 50\% of health related costs are covered by the Foundation. On a need basis, Harpswell provides motorbikes for some students to enable them to go to universities. For these students, Harpswell also covers fuel and maintenance costs.

While selecting its students, Harpswell not only considers students' economic background but also seeks out competent individuals. According to the interviews conducted, majority of the students who get selected to attend the Harpswell Foundation have to go through a competitive selection process. Harpswell's selection process is based on the candidate's national high school examination score, a written essay, and an interview. The written essay and interview are used to assess the candidate's academic excellence, leadership qualities, and passion to serve Cambodia.

\section{Role of Harpswell Foundation's Dorm Life in Creating Empowered Women}

Harpswell Foundation's dorm life is a critical factor in the personal development of its students. The daily routine at Harpswell aims to keep a balance between academic excellence and life skills. To teach life skills, different house chores are assigned to all the girls. These chores vary from cleaning, cooking, washing dishes, shopping for food supplies, organizing various events, and academic management. The assigned chores are rotated monthly so that each student has a new duty every month. The students wake up early, have their breakfast, complete their assigned house chores, and then go to university where they attend their respective classes. Classes end around noon, after which students can study in the library, or come back to the dorms and do their dorm work. To oversee the dorm work, students have a self-governing system led by various team leaders. The team leaders are elected by the students through a voting process.

In light of the interviews conducted, it was found that the students faced a variety of challenges during their initial days at Harpswell Foundation. The main challenge faced by most of the students was adapting to the pressures and workload of the daily routine at the Harpswell Foundation. Getting accustomed to the required level of socialization within the dorm was difficult for some of the more reserved students at first, but with time they developed better people skills and felt more confident. Having to make decisions about selecting majors, living away from home, and the pressures of learning multiple languages proved to be difficult for some students. However, many students reported receiving sufficient support and encouragement from their seniors, which allowed them to safely share their concerns and find solutions. The environment at Harpswell is diverse and inclusive, offering a safe space to women where they can learn from one another and meet new people. Dorm managers and sisters are always available for helping students with their problems. Another issue encountered by students was that of time management. They found it difficult to juggle both their studies and dorm work, but with time they were able to learn how to better utilize their time and complete all their assigned work. 


\section{Role of Harpswell Foundation's In-house Curriculum in Creating Empowered Women}

\section{Critical Discussion}

Qualitative analysis of the answers revealed that the critical discussion series is a defining element of Harpswell's empowerment program. These sessions are held twice a week and enable the students to broaden their knowledge and discuss the news from all over the world. Students are required to choose a news article and then present it to other students. According to students, these engaging classes have allowed them to develop the ability to think critically and learn about current affairs. Students also find these sessions helpful in improving their public speaking skills. As reported by many, critical discussions are a great way to learn from the experiences of other students, while imparting your own experiences and thoughts to others. Most students find these classes exciting and highly beneficial. The critical discussions use a paired method approach; a senior student is paired with a junior student. Often the students in each pair are from different regions and age groups. This provides an excellent opportunity for learning and growth. A drawback of the paired approach, according to the interviews, is that sometimes presenting in English is difficult for some students and often juniors are unable to understand the instructions of their seniors on how to deliver a good presentation.

\section{Mentoring}

Mentoring is another core element of the Harpswell Foundation's empowerment program. Each year Harpswell selects volunteers to serve as leadership residents. The leadership residents live at the dormitories for three to six months. In the capacity of mentors, the leadership residents are required to perform a variety of tasks. Some of these include overseeing the critical discussion sessions, scheduling a meetup time with the mentees, organizing cultural activities, and teaching subjects in the core curriculum. According to the interviews conducted, most of the mentees availed the opportunity of meeting with the leadership residents. Mentees often scheduled a session with the residents once or even twice a week, spending up to 4-5 hours per month. Even the mentees who did not spend much time interacting personally with the leadership residents had good relations with them, often praising them for their friendly and supportive nature. The analysis revealed that one-on-one meetings were scheduled with the leadership residents for various reasons. Some opted for this to improve their English while others utilized this opportunity to enhance their knowledge about a topic or to get help with assignments. Most mentees also sought a leadership resident's help for improving English writing, reading, and speaking skills. This enabled the students to be more comfortable with public speaking and to gain a sense of confidence. Few mentees also reached out to the leadership residents for getting help with a scholarship and vetting their personal statements.

\section{Core Curriculum}

Harpswell Foundation also runs in-dormitory classes comprising of six units. These are detailed below in Table 1. Core curriculum classes are generally taught from October to March. One class is held per week for a total of five weeks.

Table 1: Core Curriculum Modules

\begin{tabular}{|l|l|}
\hline Health and Nutrition (one unit) & $1^{\text {st }}$ year students \\
\hline Debate and Analytical Writing (two units) & $2^{\text {nd }}$ year students \\
\hline Job skills and Civic Engagement (two units) & $3^{\text {rd }}$ year students \\
\hline Comparative genocide studies (one unit) & $4^{\text {th }}$ year students \\
\hline
\end{tabular}




\section{Leadership Seminars}

Once every month, Harpswell Foundation invites national or international speakers who have achieved excellence or demonstrated leadership abilities in their respective domains. Respondents revealed that the leadership seminars provided a variety of benefits. Dominant amongst these were: skills development, networking, goal setting, and achieving personal excellence.

Most of the respondents felt that the seminars enabled them to understand the skills needed to become better leaders. The leaders, belonging to different walks of life, shared their struggles and success stories to motivate the girls to set high goals. The seminars not only focused on personal excellence, job success but also on various aspects of community leadership.

\section{Role of Harpswell Foundation's Programs in Developing Leadership Skills}

Many girls expressed that the environment provided by the Harpswell Foundation facilitated the development of personal, professional, and leadership skills. The dorm life encouraged intercultural connectivity by strengthening contact between women from diversified backgrounds. The overall curriculum content, interactive activities, and dorm life taught girls to be confident, expressive, and supportive towards peers. The in-house curriculum helps in producing graduates who have strong analytical, communication, and listening skills. The curriculum is also useful in creating responsible individuals that can contribute positively to the Cambodian community as leaders.

The analysis also reveals that most of the women at the Harpswell Foundation felt that their education at Harpswell has helped them transform into leaders of their community. The curriculum, critical discussions, and the interaction with inspiring individuals helped them enhance their knowledge base, encouraged them to think critically and devise strategies to attain their objectives. Most importantly, it provided insights into how they can serve the community and contribute to the economic uplift of their families and the society at large.

Many high achieving students and graduates at Harpswell win various scholarships and opportunities for studying abroad and experiencing different cultures. The most sought-after award is a fellowship to study in the U.S. Students have also been awarded opportunities to visit places like Thailand, Singapore, Indonesia, and Vietnam for different exchange programs, training programs, conferences, etc. According to the interviews, although Harpswell does not financially sponsor these scholarships, it facilitates its students in applying for scholarships, seeking financial assistance, and helping them to work for it. Harpswell Foundation assists with the passport, ticket, and pocket money for students who get a scholarship to go abroad.

Students have reported that the experience provided by Harpswell Foundation has significantly changed their worldview. It has enabled them to help out their families in financial matters. Acquiring an education and work experience has changed the way their families look at them. Most students also claim that they have a greater voice in family decisions as compared to before. Many students have actively advocated for the education of their younger siblings and some have even contributed financially towards their sibling's education. However, few think that sometimes society thinks that their independence might bring a bad name to the family, so they have to strive harder to uphold the family values and traditions.

Analysis of the respondents also reveals a strong desire to contribute to the development of Cambodia. Many students are already engaged in volunteer activities to inspire youth. Few students were also selected to represent Cambodia at international forums. Students expressed the desire to be financially independent but also to take up jobs that help towards the development of Cambodia. Donation/charity work, teaching, working for non-profits, law firms, supporting orphans, developing smart solutions to agriculture, and environmental problems were the dominant aspirations expressed by the respondents to help Cambodia. 


\section{Discussion}

The analysis revealed that the Harpswell Foundation is using a combination of various processes and programs to facilitate the empowerment of Cambodian women. By viewing the results from the lens of the conceptual framework (Figure 1), we can delineate elements that provide agency and opportunity structure. Factors that enhanced the agency of the women at Harpswell Foundation are primarily centered on the inhouse curriculum. The in-house curriculum further comprises of a core curriculum, critical discussion sessions, leadership seminars, peer support, cross-cultural and extra-curricular activities, and mentoring. Results revealed that activities carried out as part of the curriculum enabled the girls to have a broader understanding of themselves and their surroundings. This increased sense of awareness facilitated the girls in making informed choices about their personal and professional lives. As reported by the girls, there was a significant improvement in their soft skills and their sense of self awareness. For example, through focused mentoring many girls explored various scholarship and study options abroad that aligned with their area of interest. Prior to the information and support offered by mentors, the girls faced challenges in understanding how to pursue higher studies outside Cambodia. Many girls did not even initially believe that it was something they could even dare to dream.

Factors that created an opportunity structure and provided an enabling environment for empowerment include financial and residential support, a self-governing leadership system in the dorm, dorm life, jobs, internships, and volunteer opportunities. Although the curriculum designed for girls at the Harpswell Foundation contributed to their personal and professional growth, it would have been ineffective without the opportunities provided by the Foundation to put the acquired skills and knowledge to use. For example, within the dorm itself, the girls are required to exercise their leadership skills to regulate and oversee the dorm's daily activities. The girls engage in decision making, conflict resolution, and team collaboration. Outside Harpswell Foundation, girls are provided a platform to become community and professional leaders.

Results indicate that the combination of agency and opportunity structure factors result in various degrees of women empowerment at the Harpswell Foundation. Empowerment of the Harpswell women can be seen by several indicators: development of personal skills and professional skills, increase in self-awareness, enhanced worldview, economic stability, increase in family income, inclusion in family decisions, active role in development of Cambodia, achievement of scholarships, and acquisition and creation of jobs.

The thought behind Harpswell's idea of leadership aligns with the concept laid by feminist theorists which see empowerment as a combination of individual and environmental factors. Harpswell Foundation's support is pivotal in providing young women with the resources needed to enhance their individual capacity and a dorm life conducive to the growth of their leadership self. Furthermore, the programs and processes designed at the Harpswell Foundation view empowerment both as a process and an outcome that substantiates the studies conducted by Kabeer (1999), Larsson (2016), and Karim et al. (2014). This can be seen by how Harpswell structures its internal processes to enable the development of cognitive, psychological, and economic choices. This development further leads to outcomes where Harpswell graduates are seen exercising decisions that challenge their status quo in Cambodian society, increase their ability to be involved in activities that generate financial independence, and institute social change.

\section{Conclusion}

Based on countless research and the findings of this study, it is evident that empowerment is both a process and an outcome. The concept of power is central to empowerment as it highlights the ability of an agent to make purposeful choices. However, it is heavily grounded in the culture and context that it is being practiced. The combination of agency and opportunity structure can result in various degrees of empowerment. 
The study reveals that various elements can help in increasing the ability of an agent to make meaningful and purposeful choices. Harpswell enables this through its well-structured leadership and life skills curriculum. Enabling and challenging the inner ability of an individual/group is not sufficient. Providing an opportunity to exercise this ability is equally important as it can lead to the manifestation of empowered individuals/groups. Harpswell does this by providing residential assistance, various forms of financial assistance, opportunities to exercise leadership roles within the dormitory, and job opportunities. Harpswell Foundation plays a significant role in creating empowered women in Cambodia. This can be seen by the fact that most Harpswell graduates, being the first generation of their family to attend university, are either self-employed, work at a top tier company or non-profit, have pursued higher education, and/or created a significant difference in the economic conditions of their family.

\section{References}

Benería, L., \& Roldan, M. (1987). The crossroads of class and gender: Industrial homework, subcontracting, and household dynamics in Mexico City. University of Chicago Press.

Bennett, L. (2003). Empowerment and social inclusion: A social development perspective on the cultural and institutional foundations of poverty reduction. World Bank, Washington DC.

Booth, M. N. (2014). Education and gender in contemporary Cambodia. International Journal of Humanities and Social Science, 4(10), 42-50.

Cornwall, A. (2016). Women's empowerment: What works?. Journal of International Development, 28(3), 342-359.

Cornwall, A., \& Edwards, J. (2010). Introduction: negotiating empowerment. ids Bulletin, 41(2), 1-9.

Grabe, S. (2012). An empirical examination of women's empowerment and transformative change in the context of international development. American journal of community psychology, 49(1-2), 233-245.

Kabeer, N. (1999). Resources, agency, achievements: Reflections on the measurement of women's empowerment. Development and change, 30(3), 435-464.

Karim, N., Picard, M., Gillingham, S., \& Berkowitz, L. (2014). Building capacity to measure long-term impact on women's empowerment: CARE's Women's Empowerment Impact Measurement Initiative. Gender \& Development, 22(2), 213-232.

Krishna, A. (2003). Measuring Empowerment: An Analytic Framework. World Bank: Washington DC.

Larsson, A. (2016). Women's Empowerment Through the Lens of UN Women: A Qualitative Discourse Analysis from a Feminist Perspective. Retrieved from http://urn.kb.se

Malhotra, A., Schuler, S., \& Boender, C. (2002). Measuring Women's Empowerment as a Variable In International Development. Draft, PRMGE, World Bank, Washington, DC.

Rowlands, J. (1997). Questioning empowerment. Oxford: Oxfam Publications.

Sen, A. (1985). Commodities and Capabilities. Amsterdam: Elsevier.

Sen, A. (1992). Inequality Reconsidered. Cambridge, MA: Harvard University Press.

Smulovitz, C., Walton, M., \& Petesch, P. (2003). Notes on evaluating empowerment. Draft, LAC, World Bank, Washington, DC.

Smulovitz, C., Walton, M., \& Petesch, P. (2005). Evaluating empowerment: A framework with cases from Latin America. Measuring Empowerment: Cross-disciplinary Perspectives, 39-67.

Stromquist, N. P. (1999). The theoretical and practical bases for empowerment. Women, education, and empowerment: Pathways towards autonomy, 13-22.

Zimmer, Z., Konodel, J., Kim, K. S., \& Puch, S. (2005). Impact of past conflicts and social disruption in Cambodia on current generation of adults. Population Studies Center Research Report. 